\title{
Prevalence of Diabetes Mellitus Associated Chronic Kidney Disease in Ethnically Diverse Backgrounds in Western Sydney
}

Sathvik Prasad ( $\sim$ Sathvik.Prasad@health.nsw.gov.au )

Westmead Hospital https://orcid.org/0000-0003-4307-5638

Tien-Ming Hng

Blacktown Mount Druitt Hospital

Glen Maberly

Western Sydney Diabetes

Germaine Wong

Westmead Hospital

Gideon Meyerwitz-Katz

Western Sydney Diabetes

Research article

Keywords: Diabetes Mellitus, Chronic Kidney Disease, Ethnicity

Posted Date: August 6th, 2020

DOl: https://doi.org/10.21203/rs.3.rs-43607/v1

License: (9) This work is licensed under a Creative Commons Attribution 4.0 International License.

Read Full License 


\section{Abstract}

Background: Past research has demonstrated that ethnically diverse backgrounds have a greater risk of Diabetes Mellitus and/or Chronic Kidney Disease (CKD), which both contribute significantly to the disease burden placed on the Australian Healthcare system. The purpose of this study was to investigate the differences in DM associated CKD between ethnicities in Western Sydney, NSW Australia, which is known to be an ethnically diverse geographical region.

Method: Using data from Blacktown and Mt Druitt Hospitals and a retrospective approach, individuals with diabetes and CKD were identified based on $\mathrm{HbA1c}$ and eGFR results. Using univariate analysis and past research, a logistic regression modelling was carried out on the data to identify relationships between ethnicity and DM associated CKD.

Results: Out of 73,001 observations, 24,009 individuals were included in the analysis with 3,934 individuals with $\mathrm{HbA} 1 \mathrm{c}$ consistent with diabetes and kidney function at eGFR at Stage 2 and above. $47 \%$ were female and $53 \%$ were males and the median age was $76 \pm 12$ years. Using a forward-method model building process, ethnicity was compared to a reference of Caucasian. The model showed that Pacific Islanders have the most risk (OR: $5.63, \mathrm{p}<0.001, \mathrm{Cl}: 4.78-6.65)$ compared to other ethnicities. Age has an $11 \%$ increased risk per year (OR: $1.11, p<0.001, \mathrm{Cl}: 1.1-1.11$ ), men were at a $53 \%$ greater risk (OR: $1.53, \mathrm{p}$ $<0.001, \mathrm{Cl}: 1.14-1.67)$ and Aboriginal/Torres Strait Islanders were $76 \%$ more likely to have DM associated CKD (OR: 1.76, p < 0.001, Cl: 1.33-2.32). Increased socioeconomic status resulted in a $11 \%$ decreased risk in DM associated CKD (OR: 0.82, p < 0.001, Cl: 0.79-0.86) and smoking status, interestingly, also has an $18 \%$ lower risk of DM associated CKD (OR: $0.81, p=0.005, \mathrm{Cl}: 0.71-0.92)$

Conclusion: The results show a clear difference in risk between ethnicities in DM associated CKD and its associated risk factors. These differences should be accounted for when considering interventions for at risk communities.

\section{Background}

Diabetes Mellitus (DM) is a disease characterised by the body's inability to regulate blood sugar levels correctly ${ }^{(1)}$. This can lead to a range of medical complications and co-morbidities such as heart disease, nerve injury, retinopathy and also kidney disease.

Chronic Kidney Disease (CKD) rates are rising around the world and it is a growing global health problem $(2,3)$. With diabetes as a major global health burden and one of the major non-communicable diseases, the microvascular complications of diabetes compounds CKD. With DM increasing in prevalence in Australia, CKD will also correspondingly rise over the coming years contributing to the burden on the healthcare system. In 2012, CKD accounted for approximately $\$ 4.1$ billion in treatment costs, indirect costs and subsidies. Dialysis alone for CKD can cost more than $\$ 50,000$ per person per year ${ }^{(4)}$. 
Renal function in individuals with diabetes slowly deteriorates over time due to changes in the physical structure of the glomerulus in the kidneys. Initially, renal impairment may not even impact kidney function; proteinuria may be the only indication of dysfunction. This, incipient nephropathy may persist for some years before overt nephropathy develops, leading to Chronic Kidney Disease (CKD) due to DM. Over $80 \%$ of individuals with Type 1 DM can develop some degree of CKD and about $20 \%$ of individuals with Type 2 DM will progress to the point of requiring dialysis or a kidney transplant. Even with early diagnosis of diabetes and good management and control, CKD will manifest in a number of patients.

The development and progression of DM and/or CKD is complex with many contributing factors including socio-economic ones. Lifestyle and accessibility to health dietary options play a major role in in treatment, progression and management of both diseases.

Past studies ${ }^{(5-7)}$ within Australia and around the world have demonstrated that ethnically diverse populations are more susceptible to the development DM and CKD when compared to Caucasian or the native populations of other countries. Western Sydney is known to have an ethnically diverse population and identifying risk factors unique to this area would assist in planning and targeting future intervention programs or allocation of health resources to at risk communities ${ }^{(8-10)}$.

This study focuses on individuals living in the Western Sydney region who have presented to the Emergency Departments of Blacktown and Mt Druitt Hospitals. Western Sydney has an acknowledged higher rate of diabetes than other regions in the city, related to socioeconomic and other factors. Previous research has demonstrated a higher rate of diabetes than official figures suggest in this area ${ }^{(11)}$. The study population will be drawn from these individuals and will be, representative of the geographical area. The study will focus on CKD caused by DM and the effect of ethnicity and other socioeconomic factors on the prevalence of CKD within the study population.

It is hypothesised that Ethnicity, as measured by an individual's country of birth, will have a significant impact on the prevalence of CKD within the Western Sydney Region. The study will also aim to:

1. Describe the correlation between Diabetes and CKD within the study population

2. Provide insight to ethnicity and its role in DM caused CKD in Western Sydney

\section{Methodology}

\section{Study Design}

This is a cross-sectional retrospective review of 73,001 presentations to Blacktown or Mt Druitt Emergency Departments, from mid-2016 to 2018, inclusive. These patients were administered a blood test as part of their presentation and the HbA1c (glycated haemoglobin A1c) was recorded into the database, which shall be referred to as the $\mathrm{HbA} 1 \mathrm{c}$ database. The database also recorded various demographic data and the estimated Glomerular Filtration Rate (eGFR) for each presentation and other 
variables. The database is the product of a testing regime set up as routine care for patients attending the two ED's and has been running since 2016. The full testing protocol has been published elsewhere ${ }^{(11)}$.

\section{Outcome of Interest}

The outcome of interest is patients with potential kidney dysfunction and diabetes. Individuals with diabetes were identified based on $\mathrm{HbA1c}$ values and kidney dysfunction was defined as Stage 2 or higher based on eGFR. Those that meet these criteria are referred to as individuals with DM associated CKD for the purposes of this paper. The outcome variable is a coded binary variable for analysis.

\section{Inclusion/Exclusion Criteria}

Patients were included in the study if they had an $\mathrm{HbA1c}$ result and an eGFR result, along with the ethnicity recorded in the $\mathrm{HbA} 1 \mathrm{c}$ database.

Patients' repeat presentations to the emergency department were also recorded into the database but these were excluded from the study so as to keep only unique presentations.

Any patients who didn't have their ethnicity recorded, i.e. not admitted into the hospital, were also excluded from the study database.

\section{Study Population}

The following diagram shows the inclusion and exclusion of patients in the study.

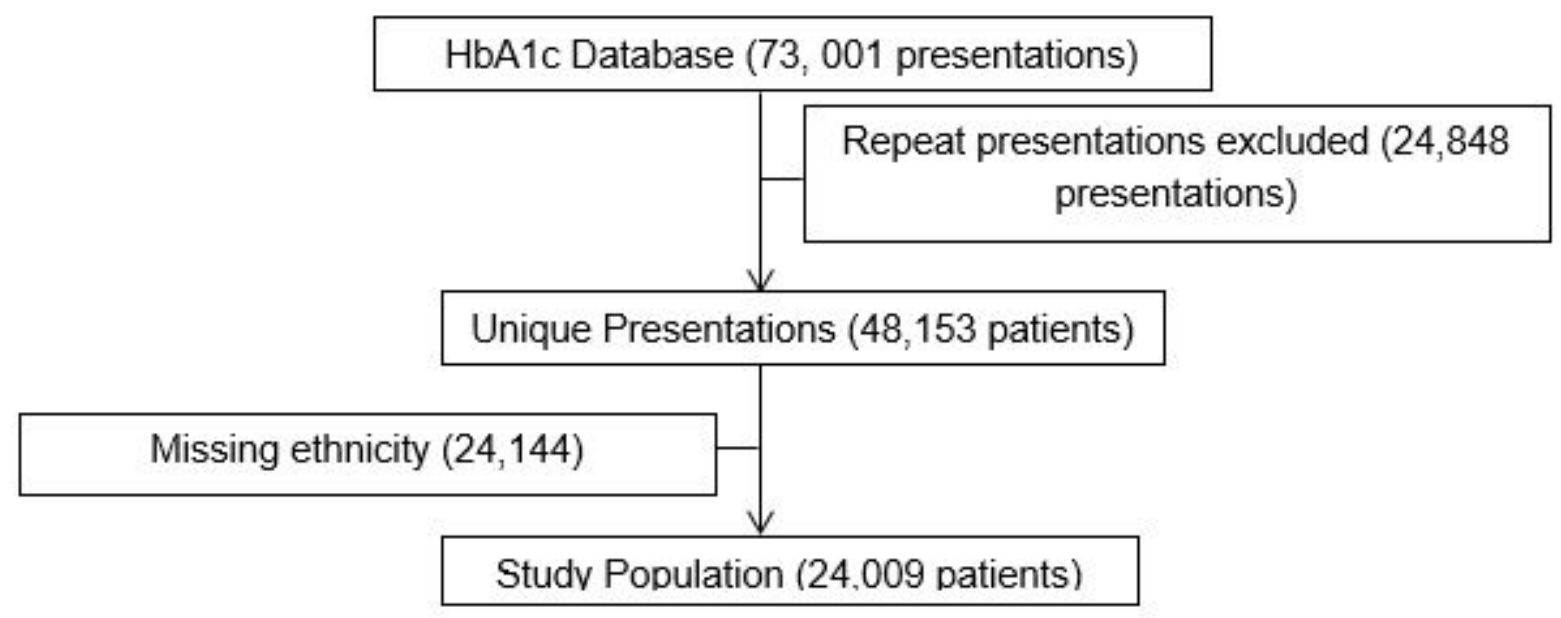

\section{Co-variates}

The $\mathrm{HbA1c}$ database recorded a number of different variables for each patient. For the purposes of this study, only the follow variables were considered.

1. HbA1c

2. eGFR 
3. Gender

4. Age

5. Ethnicity

6. Marital Status

7. Smoking Status

8. Aboriginal/Torres Strait Islander Status

9. SEIFA score (Socio-Economic Index for Areas)

10. Postcode

11. Body Mass Index (BMI)

\section{Analysis}

Data was analysed by importing relevant variables and datasets into STATA 16 statistical analysis software package. A logistical regression model was fitted to variables included for the analysis and the significance level was set at $p<0.05$. Due to the size and nature of the database, missing values were ignored in the analysis.

\section{Variables}

The eGFR result will be used to differentiate patients into stages of kidney disease as per the World Health Organisation (WHO) staging of renal impairment as per Table 1. Glycaemic categorise were allocated as per Table 2.

Table 1: eGFR and Stages of Renal Impairment

\begin{tabular}{|ll|}
\hline eGFR Result & Stage of Renal Impairment \\
\hline$>90 \mathrm{~mL} / \mathrm{min}$ & Stage 1: Normal \\
\hline $60-89 \mathrm{~mL} / \mathrm{min}$ & Stage 2: Mild \\
\hline $45-59 \mathrm{~mL} / \mathrm{min}$ & Stage 3A: Moderate \\
\hline $30-44 \mathrm{~mL} / \mathrm{min}$ & Stage 3B: Moderate \\
\hline $15-29 \mathrm{~mL} / \mathrm{min}$ & Stage 4: Severe \\
\hline$<15 \mathrm{~mL} / \mathrm{min}$ & Stage $5:$ End \\
\hline
\end{tabular}

Table 2: HbA1c and glycaemic status 


\begin{tabular}{|lll|}
\hline HbA1c(\%) & HbA1c mmol/mol & Glycaemic Status \\
\hline$\leq 5.7 \%$ & $\leq 39 \mathrm{mmol} / \mathrm{mol}$ & Normal \\
\hline $5.7-6.4 \%$ & $39-47 \mathrm{mmol} / \mathrm{mol}$ & Prediabetes \\
\hline$\geq 6.5 \%$ & $\geq 47 \mathrm{mmol} / \mathrm{mol}$ & Diabetes \\
\hline
\end{tabular}

The main explanatory variable for the study will be ethnicity, using the patient's country of birth as a surrogate measure. Other variables will be included in the analysis based on a review of past literature and a univariate analysis indicating significant correlation with diabetes associated CKD.

Socio-Economic Status was determined by importing Australian Bureau of Statistics (ABS) SEIFA values for postcodes and the SEIFA values were attached to patient postcodes in the database. SEIFA is an index of four different measures which represent different aspects of economic advantage or disadvantage. One of the SEIFA measures is the Index of Relative Socio-economic Advantage and Disadvantage (IRSAD) which was used for this study measures both advantages and disadvantages within a region.

SEIFA is measured in single unit increments, with a bell curve distribution centred over 1000 as a median value of IRSAD for a given region. For ease of interpretation, SEIFA was converted from single unit increments to 100 unit increments for analysis. A higher IRSAD score indicates a greater relative advantage verses disadvantage for an area. A lower score indicates greater disadvantage verses advantage.

The BMI variable contained many missing variables, with only approximately $12,000 \mathrm{BMIs}$ ' recorded in the database and as such was not included in the subsequent analysis. A total of 21 missing Hb1 Ac observations were also found in the database, which were not included in the analysis.

Smoking status was determined by using the ICD-10 codes F17 and Z72 which cover Nicotine Dependence and Tobacco use respectively. No differentiation was made between current and past smokers for this analysis.

\section{Model Building Process}

Variables were selected based on past literature suggesting correlation between DM and CKD. Past studies have found significant correlation between diabetes, ethnicity, age, SES status, marital status and gender, smoking status and Aboriginal/Torres Strait Islander (A/TSI) ${ }^{(7,12-16)}$. These variables were individually tested for correlation with the outcome variable with significance set at $p<0.05$. A forward method model building process was used for the analysis.

Patients were grouped together by ethnic and geographic majority as described in Table 3. Certain ethnicities such as South America for example are an amalgamation of patients whose country of birth is in the South Americas. This was done to balance the groups as certain countries were represented by very 
few patients. Likewise, a Caucasian ethnicity is represented by the Australian/North American/European group in Table 3 and is used as the base ethnicity for analysis. Table 4 contains a breakdown of each CKD stage by absolute numbers.

\section{Ethics}

This research project was approved by the Ethics Board (Application Number: 2019/ETH01985) of the Western Sydney Local Health District for the use of anonymised patient data for research and publication.

\section{Results}


Table 3

Demographics of patients within the HbA1c Database

\begin{tabular}{|ll|}
\hline Variable & Number of Patients (\%) \\
\hline Gender & \\
\hline Female & $39280(54)$ \\
\hline Male & $33721(46)$ \\
\hline Total & 73001 \\
\hline Glycaemic Status & \\
\hline Normal & $39453(54)$ \\
\hline Prediabetes & $21956(30)$ \\
\hline Diabetes & $11571(16)$ \\
\hline Total & 72980 \\
\hline Relationship Status & \\
\hline Divorced/Separated & $6795(9)$ \\
\hline Married/De-facto & $40442(55)$ \\
\hline Single & $19258(26)$ \\
\hline Unknown & $238(1)$ \\
\hline Widowed & $6268(9)$ \\
\hline Total & 73001 \\
\hline Ethnicity & $3744(10)$ \\
\hline Australian/North American/European & $24120(66)$ \\
\hline Pacific Islander & $1968(6)$ \\
\hline Asian & $3276(9)$ \\
\hline Arabic & \\
\hline African & \\
\hline South American & \\
\hline Indian/Subcontinent & \\
\hline Total & \\
\hline Smoking Status & \\
\hline Legend: (Percentage) & \\
\hline
\end{tabular}




\begin{tabular}{|ll|}
\hline Variable & Number of Patients (\%) \\
\hline No History of Smoking & $65994(90)$ \\
\hline Smoker/Ex-Smoker & $7057(10)$ \\
\hline Aboriginal/Torres Strait Islander & \\
\hline No & $69932(96)$ \\
\hline Yes & $3020(4)$ \\
\hline Legend: (Percentage) & \\
\hline
\end{tabular}

A total of 73,001 patients presented to Blacktown and Mt Druitt Emergency Departments over the three years the database covers. A further 24,848 repeat presentations are also contained within the database which were not used for the purposes of this study. The median age of patients was $48 \pm 20$ years. The mean SEIFA index was 969, with a standard deviation of 106 . Body Mass Index was also calculated to have a median of $27.58 \mathrm{~kg} / \mathrm{m}^{2}$ and a standard deviation of $8.26 \mathrm{~kg} / \mathrm{m}^{2}$. BMI however, is not included in the analysis as not all patients who presented to the Emergency Department (ED) had their BMI recorded. Only individuals admitted to the hospital from the ED had their ethnicities recorded and as a result only 24009 patients were included in the final analysis.

The ethnicity distribution of patients was then mapped to the Sydney Region (Appendix A) by their postcode of their residential address.

A total of 3,934 patients were found to have $\mathrm{HbA} 1 \mathrm{c}$ results indicating both diabetes and Stage 2 to Stage 5 kidney dysfunction. $47 \%$ were female and $53 \%$ male with the median age of $76 \pm 12$ years. Using these results, the outcome variable was coded as a binary outcome variable. Univariate analysis showed that age, gender, marital status, SEIFA, smoking status, (A/TSI) status were significantly correlated with DM associated CKD.

The final multivariate logistic regression included the variables mentioned previous except marital status. Once included in the multivariate model, marital status did not significantly correlate with the outcome when controlling for other variables. Table 3 summaries the results below. 
Table 4

Logistic Regression Results for the outcome of DM associated CKD

\begin{tabular}{|c|c|c|c|c|}
\hline Outcome: DM associated CKD & $\begin{array}{l}\text { Odds } \\
\text { Ratio }\end{array}$ & $\begin{array}{l}\text { Std. } \\
\text { Error }\end{array}$ & $\begin{array}{l}\text { p- } \\
\text { value }\end{array}$ & $95 \% \mathrm{Cl}$ \\
\hline \multicolumn{5}{|c|}{$\begin{array}{l}\text { Ethnicity(Base Group: Australian, North American/ } \\
\text { European) }\end{array}$} \\
\hline Pacific Islander & 5.63 & 0.48 & $<.001$ & $\begin{array}{l}4.78- \\
6.65\end{array}$ \\
\hline African & 2.18 & 0.25 & $<001$ & $\begin{array}{l}1.74- \\
2.73\end{array}$ \\
\hline Asian & 1.91 & 0.14 & $<.001$ & $\begin{array}{l}1.66- \\
2.21\end{array}$ \\
\hline Indian/Subcontinent & 1.89 & 0.15 & $\begin{array}{l}< \\
0.001\end{array}$ & $\begin{array}{l}1.62- \\
2.22\end{array}$ \\
\hline Arabic & 1.42 & 0.14 & 0.001 & $\begin{array}{l}1.16- \\
1.75\end{array}$ \\
\hline South American & 0.61 & 0.13 & 0.016 & $\begin{array}{l}0.40- \\
0.91\end{array}$ \\
\hline A/TSI & 1.76 & 0.25 & $<001$ & $\begin{array}{l}1.33- \\
2.32\end{array}$ \\
\hline Gender (Male) & 1.53 & 0.07 & $<.001$ & $\begin{array}{l}1.139- \\
1.67\end{array}$ \\
\hline Age & 1.11 & 0.002 & $\begin{array}{l}< \\
0.001\end{array}$ & $1.1-1.11$ \\
\hline Smoker/Ex-Smoker & 0.81 & 0.05 & 0.005 & $\begin{array}{l}0.71- \\
0.92\end{array}$ \\
\hline SEIFA & 0.82 & 0.02 & $\hat{0}_{0.001}$ & $\begin{array}{l}0.79- \\
0.86\end{array}$ \\
\hline
\end{tabular}


Table 5

Number of patients by ethnicity and eGFR stage

\begin{tabular}{|c|c|c|c|c|c|c|c|c|}
\hline & $\begin{array}{l}\text { Australian/ } \\
\text { Caucasian }\end{array}$ & $\begin{array}{l}\text { India/ } \\
\text { Subcontinent }\end{array}$ & Asian & $\begin{array}{l}\text { Pacific } \\
\text { Islander }\end{array}$ & Arabic & African & $\begin{array}{l}\text { South } \\
\text { America }\end{array}$ & Total \\
\hline \multicolumn{9}{|l|}{$\begin{array}{l}\text { CKD } \\
\text { Stage }\end{array}$} \\
\hline $\begin{array}{l}\text { Stage } \\
1\end{array}$ & $13,041(64)$ & 2,577 (13) & $\begin{array}{l}1,777 \\
(9)\end{array}$ & $953(5)$ & $\begin{array}{l}972 \\
(5)\end{array}$ & $685(3)$ & $215(1)$ & $\begin{array}{l}20,220 \\
(100)\end{array}$ \\
\hline $\begin{array}{l}\text { Stage } \\
2\end{array}$ & $6,810(68)$ & 767 (8) & $\begin{array}{l}923 \\
(9)\end{array}$ & $602(6)$ & $\begin{array}{l}392 \\
(4)\end{array}$ & $326(3)$ & $144(2)$ & $\begin{array}{l}9,964 \\
(100)\end{array}$ \\
\hline $\begin{array}{l}\text { Stage } \\
3 A\end{array}$ & $1,752(71)$ & $137(6)$ & $\begin{array}{l}204 \\
(8)\end{array}$ & $161(7)$ & 73 (3) & $104(4)$ & $36(1)$ & $\begin{array}{l}2,467 \\
(100)\end{array}$ \\
\hline $\begin{array}{l}\text { Stage } \\
3\end{array}$ & $1,160(71)$ & $99(6)$ & $\begin{array}{l}131 \\
(8)\end{array}$ & $94(6)$ & $52(3)$ & $69(4)$ & $22(2)$ & $\begin{array}{l}1,627 \\
(100)\end{array}$ \\
\hline $\begin{array}{l}\text { Stage } \\
4\end{array}$ & 525 (69) & $34(4)$ & $\begin{array}{l}86 \\
(11)\end{array}$ & $54(7)$ & $22(3)$ & $35(5)$ & $4(1)$ & $\begin{array}{l}760 \\
(100)\end{array}$ \\
\hline $\begin{array}{l}\text { Stage } \\
5\end{array}$ & 247 (61) & $26(6)$ & $\begin{array}{l}52 \\
(13)\end{array}$ & $53(13)$ & $13(3)$ & $14(3)$ & $4(1)$ & $\begin{array}{l}409 \\
(100)\end{array}$ \\
\hline Total & $23,535(66)$ & 3,640 (10) & $\begin{array}{l}3,173 \\
(9)\end{array}$ & $\begin{array}{l}1,917 \\
(5)\end{array}$ & $\begin{array}{l}1,524 \\
(4)\end{array}$ & $\begin{array}{l}1,233 \\
(3)\end{array}$ & $425(1)$ & $\begin{array}{l}35,447 \\
(100)\end{array}$ \\
\hline
\end{tabular}

\section{Discussion}

Table 5 above shows the rates of patients at each eGFR stage by ethnicity. The base ethnicity of Australian/Caucasian contains the most number of people at each stage of kidney function, followed by Indian/Subcontinent, Asian, Arabic, African and lastly, South American.

From the results in Table 4, Pacific Islanders are most at risk, when compared to the base group, with more than 5 times the risk of having DM associated CKD, when adjusting for the other variables. African ethnicities were twice (OR: $2.18 p<0.001)$ as likely followed by Asian (OR: 1.91, $p<0.001)$ and Indian/Subcontinent (OR: 1.89, $\mathrm{p}<0.001)$ ethnicities.

Marital status had no significant correlation with DM associated CKD once included in the multivariate analysis, therefore, was not reported. While marital status has been found to correlate with diabetes in other studies, this has not been replicated in this study. Age was also correlated with an increase in DM associated CKD, with an $11 \%$ increase, per year, controlling for other variables. Conversely DM associated CKD has an $18 \%$ reduction, per 100 unit increase in SEIFA, controlling for other variables, indicating that access to improved socioeconomic resources can reduce DM associated CKD prevalence. 
Gender also has a significant effect with men having a 53\% increased risk of DM associated CKD when compared with women, controlling for other variables. Finally, Aboriginal/Torres Strait Islander individuals seem to have a $76 \%$ greater risk of DM associated CKD, controlling for other variables. This significant risk could be due to the unique socio-economic and cultural factors associated Aboriginal communities and individuals. Some examples are lower levels of access/utilisation of resources such as education, health services and a higher rate of detrimental health behaviours such as smoking and alcohol consumption ${ }^{(17)}$.

Smoking was also interestingly, associated with a 19\% reduction in the risk of DM associated CKD when compared to individuals who had never smoked. This is odd as smoking is a major risk factor of both diabetes and kidney disease, therefore an increased risk is to be expected. This could be explained by considering that most individuals with diabetes and renal impairment are given medical advice to quit smoking. This could result in a lower odds ratio associated with smoking, indicating possible survivor bias $^{(16)}$. Alternatively, access to better and more frequent medical care could also explain the results, again, indicating survivor bias.

Figure 1, Appendix A, contains maps of geographic distribution of patients presenting to the hospitals, generated from the $\mathrm{HbA} 1 \mathrm{c}$ database. These maps indicate that most individuals present to the hospitals from close geographical locations. While there are people presenting from distant geographical locations, this only represents a small number of the total patients. These "distant patients" however, proportionally have more diabetes and is curious that they present to Mt Druitt and Blacktown Hospitals, when there are many other hospitals in closer proximity to their residence.

The maps in Fig. 1 also show that ethnicity is also highly varied around the Western Sydney regions with large localised populations within close geographical proximity to Blacktown hospital. This highlights the diverse multicultural community that these hospitals serve and the challenges it brings. Understanding the needs of the community and its needs will allow for better provision of healthcare and allocation of resources.

These study's strengths are the large sample size that powers the study with over 24,000 individuals included in the analysis. This large sample size also suggests a good representation of the target population in Western Sydney. The results are thus more generalizable for Western Sydney and are very relevant for planning of targeted health interventions in the region. The database was also flexible, with clinical information for analysis and socio-economic data as well, allowing for a more in depth modelling.

One of the main limitations of the study is using country of birth as a surrogate measure for ethnicity. Immigrants have risks from their country of origin due to differences in diet lifestyle factors. This risk difference gradually diminishes as successive generations as they naturalise to the local population, but still can persist within close-knit ethnic communities ${ }^{(12)}$. The Caucasian ethnicity coding used for our analysis did not take this into account as it grouped together any individuals born in Australia, disregarding the birthplace of their parents, which are major source of cultural risk factors. Linguistically 
diverse backgrounds were also not considered as part of this study. The lack of certain ethnicities is also an issue such as the South American (1\%). It is uncertain if this underrepresentation is reflective of the data or of the actual population of these ethnicities within the Western Sydney region.

The second limitation in this study is the reliance on a single biochemical measurement to define diabetes and CKD. Whilst elevated HbA1c levels may indicate diabetes, low levels can be present in diabetics with good glucose control and misclassification. Similarly, low eGFR may represent CKD but is not diagnostic and can be due to transient conditions. The causality between concurrent diabetes and CKD has not been confirmed for this study and should not be assumed. BMI and physical activity levels have not been controlled for in this study.

\section{Conclusion}

Certain ethnicities are more at risk from DM associated CKD than others and the study highlights this difference in epidemiology between ethnicities in the Western Sydney and some of the associated risk factors. The increased risk of DM associated CKD with certain ethnicities show that interventions targeting CKD directly or even diabetes and lifestyle changes should be tailored to better suit the target demographic. Cultural and language barriers may reduce the efficacy of self-management of chronic conditions and interventions that address ethnic differences as part of the program have more success that ones that do not ${ }^{(18)}$. The findings of this study can be used as a starting point for planning and directing more targeted interventions for the communities most at risk.

\section{Abbreviations}

DM: Diabetes Mellitus

CKD: Chronic Kidney Disease

SEIFA: Socio-Economic Indexes for Areas

ISRAD: Index of Relative Socio-economic Advantage and Disadvantage

BMl: Body Mass Index

\section{Declarations}

\section{Ethics Approval and Consent for Publication/Participate}

This research project was approved by the Ethics Board of the Western Sydney Local Health District (Application Number: 2019/ETH01985) for the use of anonymised patient data for research and publication. A wavier was allowed for contacting participants consent as only de-identified data was used research and publication purposes. 


\section{Competing interests}

No competing interests to declare.

\section{Availability of Data and Materials}

The $\mathrm{HbA} 1 \mathrm{c}$ data used in this study is not available for publication. Socio-economic and ethnicity data was acquired from the Australian Bureau of Statistics. (https://www.abs.gov.au/)

STATA 16 used to analyse the data is available at https://www.stata.com for purchase.

\section{Competing Interests}

No competing interests to declare for the authors.

\section{Funding}

This research was possible by the support of Western Sydney Diabetes (WSD) and The University of Sydney. No monetary funding was received for this research.

\section{Authors' Contribution}

GMK coded the $\mathrm{HbA1c}$ database and the coding for ethnicities and assisted in the analysis. SP conducted literature review, analysis and writing the paper for their Master's degree via the University of Sydney. TMH, GW and GM contributed their speciality knowledge for the manuscript. All authors have read and approved the final manuscript.

\section{Acknowledgements}

Special thanks to Dr Glen Maberly, Dr Tien-Ming Hng, Dr Germine Wong and Gideon Meyerowitz-Katz for their input and guidance.

\section{Author Information}

SP: Nuclear Medicine Technologist, Westmead Hospital, Sydney, NSW Australia.

TMH: Staff Endocrinologist and Head, Diabetes and Endocrinology, Blacktown Mt Druitt Hospital, Sydney, NSW Australia. Conjoint Senior Lecturer, Western Sydney University.

GM: Senior Staff Specialist Endocrinologist at Blacktown and Mt Druitt Hospitals and Program Lead for Western Sydney Diabetes initiative

GW: Director of Renal and Transplant Medicine, Senior Transplant Specialist, Westmead Hospital.

GMK: Epidemiologist, Research, Monitoring, and Surveillance Coordinator for Western Sydney Diabetes. 


\section{References}

1. WHO Global Report on Diabetes. Executive Summary [press release]. World Health Organisation2016.

2. Beagley J, Guariguata L, Weil C, Motala AA. Global estimates of undiagnosed diabetes in adults. Diabetes Res Clin Pract. 2014;103(2):150-60.

3. Zimmet P, Alberti KGMM, Shaw J. Global and societal implications of the diabetes epidemic. Nature. 2001;414(6865):782-7.

4. Kidney Fast Facts: Kidney Health Australia; 2018 [Available from:

https://kidney.org.au/cms_uploads/docs/kidney-fast-facts-fact-sheet.pdf.

5. Thompson RJ. Deprivation and ethnicity impact on diabetes control and use of treatment regimen. Diabetic medicine. 2013;30(4):491-4.

6. Oza-Frank R, Chan C, Liu K, Burke G, Kanaya AM. Incidence of type 2 diabetes by place of birth in the Multi-Ethnic Study of Atherosclerosis (MESA). J Immigr Minor Health. 2013;15(5):918-24.

7. Scheuing N, Wiegand S, Bächle C, Fröhlich-Reiterer E, Hahn E, Icks A, et al. Impact of Maternal Country of Birth on Type-1-Diabetes Therapy and Outcome in 27,643 Children and Adolescents from the DPV Registry. PLOS ONE. 2015;10(8):e0135178.

8. Manini TM, Carr LJ, King AC, Marshall S, Robinson TN, Rejeski WJ. Interventions to Reduce Sedentary Behavior. Med Sci sports Exerc. 2015;47(6):1306-10.

9. Kahn EB, Ramsey LT, Brownson RC, Heath GW, Howze EH, Powell KE, et al. The effectiveness of interventions to increase physical activity: A systematic review. American Journal of Preventive Medicine. 2002;22(4, Supplement 1):73-107.

10. Cradock KA, ÓLaighin G, Finucane FM, Gainforth HL, Quinlan LR, Ginis KAM. Behaviour change techniques targeting both diet and physical activity in type 2 diabetes: A systematic review and metaanalysis. International Journal of Behavioral Nutrition and Physical Activity. 2017;14(1).

11. Meyerowitz-Katz G, Seelan S, Gaur P, Francisco R, Ferdousi S, Astell-Burt T, et al. Detecting the hidden burden of pre-diabetes and diabetes in Western Sydney. Diabetes Res Clin Pract. 2019;151:247-51.

12. Chaturvedi N. Ethnicity as an epidemiological determinant-crudely racist or crucially important? Int J Epidemiol. 2001;30(5):925-7.

13. Christensen DL, Witte DR, Kaduka L, Jørgensen ME, Borch-Johnsen K, Mohan V, et al. Moving to an A1C-Based Diagnosis of Diabetes Has a Different Impact on Prevalence in Different Ethnic Groups. Diabetes Care. 2010;33(3):580.

14. Christine PJ, Auchincloss AH, Bertoni AG, Carnethon MR, Sánchez BN, Moore K, et al. Longitudinal Associations Between Neighborhood Physical and Social Environments and Incident Type 2 Diabetes Mellitus: The Multi-Ethnic Study of Atherosclerosis (MESA). JAMA Intern Med. 2015;175(8):1311-20.

15. Rabi DM, Edwards AL, Southern DA, Svenson LW, Sargious PM, Norton P, et al. Association of socioeconomic status with diabetes prevalence and utilization of diabetes care services. BMC Health Services Research. 2006;6(1):124. 
16. Practitioners TRACoG. Type 2 diabetes: Goals for optimum management. The Royal Australian College of General Practitioners; 2016.

17. Booth, ALaC, Nick. The Health Status of Indigenous and Non-Indigenous Australians. IZA Discussion Paper No 1534. 2005.

18. Ricci-Cabello I, Ruiz-Pérez I, Rojas-García A, Pastor G, Rodríguez-Barranco M, Gonçalves DC. Characteristics and effectiveness of diabetes self-management educational programs targeted to racial/ethnic minority groups: a systematic review, meta-analysis and meta-regression. BMC Endocrine Disorders. 2014;14(1):60.

\section{Supplementary Files}

This is a list of supplementary files associated with this preprint. Click to download.

- AppendixA.docx 